\title{
A FORMAÇÃO DE PROFESSORES EM SERVIÇO: POLÍTICAS DE ALINHAMENTO AOS ORGANISMOS INTERNACIONAIS E À LÓGICA NEOLIBERAL
}

\author{
LA FORMACIÓN DE PROFESORES EN SERVICIO: POLÍTICAS DE ALINEACIÓN A \\ LOS ORGANISMOS INTERNACIONALES Y LA LÓGICA NEOLIBERAL
}

\author{
FORMATION TEACHERS IN SERVICE: ALIGNMENT OF POLICIES TO \\ INTERNATIONAL ORGANIZATIONS AND LOGIC NEOLIBERAL
}

\author{
Clarice ZIENTARSKI ${ }^{1}$ \\ Perla de Almeida FREIRE ${ }^{2}$ \\ Maria Aires de LIMA ${ }^{3}$
}

RESUMO: Este estudo é parte integrante do projeto PIBIC/UFC/FUNCAP, intitulado: “ $A$ formação continuada dos professores no contexto de democratização da gestão escolar na rede municipal de Fortaleza, Ceará, Brasil", que tem por objetivo identificar as ações e propostas que envolvem os processos de formação continuada de professores a partir dos diferentes espaços formativos. Trata-se de pesquisa com abordagem qualitativa, tendo como instrumentos a pesquisa documental e entrevistas semiestruturadas com professores e outros componentes da comunidade escolar. $\mathrm{Na}$ análise dos dados, o aporte teórico de sustentação é o histórico dialético, para tentar chegar à compreensão da realidade investigada. Como resultados parciais, tendo como objetos onze escolas da rede municipal e seus segmentos, constata-se que as políticas de formação de professores e as ações em andamento sinalizam para o alinhamento das formações, que atendem às prerrogativas legais, organismos internacionais e ideário neoliberal.

PALAVRAS-CHAVE: Formação continuada de professores. Organismos internacionais. Neoliberalismo.

RESUMEN: Este estudio es parte integrante del proyecto PIBIC / UFC / FUNCAP, titulado: "La formación continuada de los profesores en el contexto de democratización de la gestión escolar en la red municipal de Fortaleza, Ceará, Brasil", que tiene por objetivo identificar las acciones y propuestas que involucra Los procesos de formación continuada de profesores a partir de los diferentes espacios formativos. Se trata de una investigación con enfoque cualitativo, teniendo como instrumentos la investigación documental y entrevistas

\footnotetext{
${ }^{1}$ Universidade Federal do Ceará (UFC), Fortaleza - CE. Doutora em Educação Professora do Departamento de Fundamentos da Educação- UFC-Coordenadora Escola da Terra- Professora e Pesquisa da Pós-Graduação em Educação Brasileira. Departamento de Fundamentos da Educação. OrcID: http://orcid.org/0000-0002-84535429. E-mail: claricezientarski@yahoo.com.br

${ }^{2}$ Universidade Federal do Ceará (UFC), Fortaleza - CE. Departamento de Fundamentos da Educação. Pedagoga - Mestre em Educação. Formadora da Escola da Terra- Ceará. OrcID: https://orcid.org/0000-0002-4388-0832. Email: perlaalmeida.freire@gmail.com

${ }^{3}$ Universidade Federal do Ceará (UFC), Fortaleza - CE. Doutoranda e Mestra em Educação pelo Programa de Pós-graduação em Educação - PPGE/UECE. OrcID: https://orcid.org/0000-0003-4463-1691. E-mail: mariaaires@ hotmail.com
}

RIAEE - Revista Ibero-Americana de Estudos em Educação, Araraquara, v. 14, n. 4, p. 2160-2174, out./dez., 2019. e-ISSN: 1982-5587. 
semiestructuradas con profesores y otros componentes de la comunidad escolar. En el análisis de los datos el aporte teórico de sustentación es el histórico dialéctico, para intentar llegar a la comprensión de la realidad investigada. Como resultados parciales, teniendo como objetos once escuelas de la red municipal y sus segmentos, se constata que las politicas de formación de profesores y las acciones en marcha señalan para el alineamiento de las formaciones, que atienden a las prerrogativas legales, organismos internacionales e ideario neoliberal.

PALABRAS CLAVE: Formación continuada de profesores. Organismos internacionales. Neoliberalismo.

ABSTRACT: This study is part of PIBIC / UFC / FUNCAP project entitled: "The continuing formation of teachers in the context of democratization of the school management in municipal network of Fortaleza, Ceará, Brazil", which aims to identify actions and proposals involving the continuing formation process of teachers from different training areas. This is a qualitative approach research; the instruments used were documentary research and semistructured interviews with teachers and other components of the school community. In the data analysis the theoretical basis of support is the historical dialectic, to try to reach an understanding of the investigated reality. As partial results with the objects, eleven schools of the municipal network, and their segments, it appears that teacher formation policies and actions in progress signal to the alignment of education and training to meet the legal powers, international organizations and neoliberal ideology.

KEYWORDS: Continuing formation of teacher. International Organizations. Neoliberalism.

\section{Introdução e pressupostos metodológicos}

A formação continuada de professores em serviço, elemento em análise neste trabalho, faz parte de um conjunto de mudanças propostas pela Legislação Educacional e nas determinações dos organismos internacionais em uma conjuntura neoliberal, o que representa, por um lado, um grande desafio para as instituições escolares, por constituir-se em um espaço formativo desenvolvido na própria escola e, por outro lado, podem ser um indicativo de fragilidade na formação, tendo em vista o distanciamento do ambiente universitário e da perspectiva científica e acadêmica (SHIROMA, 2003), ou ainda, uma ferramenta importante de legitimação das contradições próprias ao modelo de sociedade do capital. Estas afirmações, portanto, constituem-se como hipóteses centrais do referido estudo.

Assim, tendo em vista estas premissas, a discussão neste artigo busca subsídios teóricos que tratam da temática, pois compreende e reconhece a importância da análise científica e filosófica. Realiza análise documental e, como instrumentos e técnicas de pesquisa, são efetivadas entrevistas semiestruturadas com professores da rede pública municipal e outros componentes da comunidade escolar, buscando a elucidação das hipóteses, 
tendo como campo empírico, neste caso específico, onze escolas da rede escolar municipal de Fortaleza, CE, localizadas em bairros da periferia e centro da cidade e 32 professores das referidas escolas. A pesquisa foi realizada durante o ano de 2014 e 2015, com ênfase em 2015, tendo em vista que foi o período de realização das entrevistas com os professores das escolas objeto de estudo e análise.

No que se relaciona à pesquisa documental, Moreira (2005) sublinha que a análise documental deve extrair uma representação objetiva da fonte original, permitir a localização, identificação, organização e avaliação das informações contidas no documento, além da contextualização dos fatos em determinados momentos. Por fim, tendo em vista a necessidade da aproximação da pesquisa empírica com a discussão teórica, especialmente na interpretação dos dados, a investigação se apoia no referencial de análise histórico-dialético, sendo esse compreendido como uma forma de pensamento crítico que se propõe a conhecer sistematicamente a coisa em si e se perguntar como é possível chegar à compreensão da realidade (KOZIK, 1985, p. 17).

O trabalho parte de alguns questionamentos, tendo em vista que a legislação ao contemplar a formação continuada de professores como uma das prerrogativas para a melhoria da qualidade da educação faz com que o processo formativo assuma grande importância: as escolas do município de Fortaleza oferecem atividades que proporcionem constante atualização de seus profissionais, cuja ênfase recaia nas políticas educacionais, nos princípios da gestão em seu caráter administrativo-político-pedagógico, dentre outros aspectos, o que envolve, diretamente, a formação continuada de professores em serviço? A gestão municipal de Fortaleza tem realizado ações que evidenciem compromissos em relação à formação continuada de seus professores? As ações formativas têm perspectiva científica e acadêmica? Qual o referencial teórico que fundamenta as formações?

Neste trabalho, conforme salientado anteriormente, sublinha-se a intenção de conhecer e contribuir com o processo de ocupação planejada, sistemática e a apropriação destes espaços de formação continuada para professores e, para tanto, discute-se inicialmente a política de formação continuada de professores no Brasil.

\section{A formação de professores no Brasil: breves discussões}

A formação de professores apresenta-se como resultado de uma política induzida externamente, resultado de pactos, acordos e agendas internacionais e que revelam um 
profundo caráter prescritivo, apresentando verdadeiras "receitas" de como os professores devem ser formados, em quais concepções e para qual projeto de sociedade.

O processo de formação de professores no Brasil nos últimos anos passou por alterações, e o paradigma de formação em que o professor tem o papel de transmitir os conhecimentos socialmente elaborados e organizados pelo conjunto dos homens passa a ser qualificado como tradicional, arcaico, obsoleto e não condizente com as novas demandas exigidas pela sociedade. Esses posicionamentos, portanto, apontavam para o declínio da pedagogia tradicional.

As alterações passaram a ser mais acentuadas a partir da década de 1990, período em que várias nações do mundo foram convocadas a participar de um esforço coletivo e estipular metas e estratégias imprescindíveis à adequação da educação ao modelo econômico vigente e ao ideário neoliberal. Uma das ações realizadas com este intento foi a Conferência Mundial de Educação para Todos, realizada em Jomtien, na Tailândia, em 1990, sob a indicação e "cuidados" da Organização das Nações Unidas - ONU.

Leher (1999) afirma que por conta das parcerias entre os organismos internacionais e governos, a UNESCO, em meados dos anos 1980, ao perder o posto de gerência dos negócios educacionais, assumiu o princípio pedagógico do novo senhor da educação. No Brasil, convém salientar que desde a década de 1960 a UNESCO tem realizado projetos de cooperação técnica, em estreita relação entre segmentos da sociedade civil e o governo brasileiro. Estas parcerias oficializaram-se com o governo civil militar, que com o intuito de modernizar a educação brasileira, ampliou o processo de dependência do país ao capital internacional e exerceu a supervisão sobre as ações políticas e educacionais do Brasil.

O objetivo maior destes projetos de cooperação técnica são a formulação e a operacionalização das políticas públicas destas áreas, em consonância com as metas acordadas entre os Estados Membros das Nações Unidas. A UNESCO também coopera com diferentes instâncias da sociedade civil e com o setor privado, tendo em vista os propósitos de desenvolvimento humano da ONU.

A presença dos organismos internacionais, especialmente do Banco Mundial, na educação brasileira, efetiva-se desde a década 1960, o que podemos confirmar com as asseverações de Muniz e Arruda citados por Silva:

[...] a política do Banco Mundial pode ser localizada nos anos de 1960 e 1970 quando houve uma acelerada expansão da educação e o aumento dos índices de matrícula dos países devedores [...] e da disseminação da ideia de melhoria do status social, vinculado à educação, e da concepção de que a 
educação geraria empregos e desenvolvimento econômico (SILVA, 2002, p. $63)$.

Entre os objetivos dos acordos estabelecidos pelos organismos e os governos brasileiros salienta-se o inegável interesse em fortalecer essa associação, através da concessão e persuasão destes organismos internacionais, cujas ações e acordos, firmados entre o governo norte-americano e o brasileiro, deixam claro o interesse dos Estados Unidos da América em constituírem forças para a consolidação do capitalismo internacional (ROMANELLI, 1986).

Com relação à educação, as propostas do Banco Mundial (BM) deveriam ser realizadas como uma forma de compensar a situação de pobreza que o país se encontrava ao passar pelos ajustes econômicos. Esse seria um mecanismo fundamental, por meio do qual seria possível adquirir um novo padrão de acúmulo do capital. Percebe-se, com tais colocações, que o Banco Mundial tem participado direta e sistematicamente no âmbito educacional, com "capacidade de intervir e formular políticas educacionais para a América Latina, manipulando os benefícios tirados das políticas sociais” (SILVA, 2002, p. 58).

A suposta modernização dos sistemas educativos decorreria da "criação de uma base de recursos humanos na área da gestão" (UNESCO, 1998, p. 5) e da profissionalização da ação dos ministérios, bem como das escolas e dos professores em sala de aula (CASSASSUS, 1995, p. 105). O Brasil, como se pode verificar pela própria legislação educacional, incorporou estas orientações. A formação de professores no Brasil atende ao cumprimento das Metas relativas à valorização dos profissionais da educação, estabelecida pelo Plano Nacional de Educação (Lei nº ${ }^{\circ}$ 13.005/2014), alicerçada na Lei do Piso Salarial Profissional Nacional para os Profissionais do Magistério Público da Educação Básica (Lei nº 11.738/2008), Lei de Diretrizes e Bases da Educação Nacional (Lei nº 9.394/1996), Constituição Federal Brasileira (CF) de 1988, entre outros Decretos e Resoluções.

Dentre as ações previstas, merece relevância a formação e as políticas de profissionalização dos professores, por meio do estabelecimento de diretrizes e documentos, orientados sob os auspícios dos organismos internacionais para a formação inicial e a formação continuada em serviço.

\section{A formação continuada de professores: as prerrogativas legais e as orientações dos organismos internacionais}

Nos anos de 1990, sobretudo no governo de Fernando Henrique Cardoso - FHC, as reformas e a reestruturação produtiva, como salientam Shiroma, Moraes e Evangelista (2007, 
p. 78), "não deixaram de fazer uso dos recursos disponibilizados por seu farto arsenal legislativo". As ações contra o "caráter público da universidade, iniciadas ainda no regime militar, encontram incentivos e reforços nunca vistos”. As autoras salientam que antes da LDB nº 9.394/96 e depois dela, um grande número de leis, decretos, decretos-leis, portarias, resoluções passaram a definir os rumos do ensino superior no Brasil. Esses documentos, de uma maneira geral, contribuíram para comprometer e avaliar o professor, porém limitaram a formação.

Um dos exemplos que ratificam esta afirmação pode ser constado no documento intitulado: "Questões Críticas da Educação Brasileira” publicado no ano de 1995, no governo do presidente Fernando Henrique Cardoso, que deixa claro o envolvimento empresarial e a "representação governamental" na definição de ações para a formação de professores, à medida que busca:

[...] superar a discussão sobre a qualidade na educação, do ponto de vista restrito da melhoria da gestão do sistema educacional e de seus instrumentos específicos, para alcançar consensos mais estruturais sobre a busca de um sistema educacional integrado às exigências qualitativas do setor produtivo $\mathrm{e}$ da sociedade (BRASIL, UFV, 1995, p. 3).

O referido documento formulava estratégias de atuação do PACTI - PROGRAMA DE APOIO À CAPACITAÇÃO TECNOLÓGICA DA INDÚSTRIA e do PBQP - PROGRAMA BRASILEIRO DA QUALIDADE E PRODUTIVIDADE na área educacional, cujo objetivo era a busca e "a adequação dos objetivos educacionais às novas exigências do mercado internacional e interno, e, em especial, na consolidação do processo democrático no que concerne à formação do cidadão-produtivo" (BRASIL, UFV, 1995, p. 3). As recomendações presentes nesse documento se encontram em sintonia com as orientações dos organismos internacionais e incorporam instrumentos de descentralização e de desobrigação do poder público com as políticas sociais. Isso pode ser vislumbrado no documento quando salienta que as instituições convidadas a participar das reuniões de definição das ações são:

O DIEESE - Departamento Intersindical de Estatística e Estudos Socioeconômicos, o Sistema CNI/IEL/SENAI [Sistema Indústria, que abrange o Serviço Social da Indústria (SESI), o Serviço Nacional de Aprendizagem Industrial (SENAI) e o Instituto Euvaldo Lodi], o MEC Ministério da Educação e, por último, os Governos Estaduais, através dos fóruns de Secretários de Educação e dos Secretários de Indústria e Comércio (BRASIL, UFV, 1995).

Nesta esteira, compreende-se o tipo de recomendações para a formação de professores, que são os responsáveis por formar este "cidadão-produtivo" que as empresas precisam 
receber para realizar a "produtividade sistêmica, que está presente na produção" [...]. O que “implica na visão e tratamento articulados das questões sociais e econômicas e de aspectos de infraestrutura, como pré-condição ao sucesso de um projeto de reestruturação produtiva (BRASIL, UFV, p. 7)".

Neste enfoque, Saviani (2000) chama a atenção para o fato de que a lógica mercantil assume cada vez mais um papel fundamental e determinante no campo da educação, e os organismos internacionais (UNESCO, UNICEF, BANCO MUNDIAL e FMI, etc.), cujas palavras de ordem são qualidade, produtividade e equidade, com a máxima racionalização e otimização dos recursos já existentes, são encarregados de ditar os parâmetros na área educacional. A lógica produtivista ao mesmo tempo em que invade o espaço educativo responsabiliza os professores e as escolas pelo fracasso educacional.

A premissa, portanto, é a de que a crise educacional brasileira afeta a economia e por esta razão deve ser enfrentada, sendo que para tal empreitada conta com a legislação e a política educacional em seu conjunto, o que envolve tanto a formação inicial de professores quanto a formação continuada. A formação de professores deveria então inserir-se nesta lógica, sendo orquestrada de maneira a responder às exigências mercadológicas: ao atribuir ao professor mais responsabilidades e funções, deveria também provocar mudanças na sua formação. Kuenzer afirma:

[...] as demandas de formação de professores respondem a configuração que se originam nas mudanças ocorridas no mundo do trabalho e nas relações sociais, e a configurações oriundas das diferentes posições que são assumidas em relação aos projetos apresentados pelo grupo que ocupa o poder a partir de determinada correlação de forças. [...] cada etapa de desenvolvimentos social e econômico correspondem projetos pedagógicos, aos quais correspondem perfis diferenciados de professores, de modo a atender às demandas dos sistemas social e produtivo com base na concepção dominante (KUENZER, 1999, p. 166).

Nesse contexto, a formação de professores precisa assumir um papel e formar um profissional que desenvolva competências e a capacidade para lidar com o imediato, resolver problemas, conduzindo a ação educativa em consonância com a prática. Com esse tipo de formação não se exige nem o rigor, nem a análise, nem o aprofundamento que se exigiria normalmente nos cursos de formação.

As autoras citam o Decreto $n^{\circ}$. 3.276/1999 para afirmar que os centros, institutos, setores ou faculdades de educação são "estimulados a oferecer cursos normais superiores e abandonar a formação docente em cursos de pedagogia". Já o curso de pedagogia deve dedicar-se ao "preparo de especialistas, particularmente gestores educacionais, de que o 
projeto governamental não pode prescindir para asseverar o bom resultado da política”. Este decreto, sublinham as autoras, é prejudicial à formação docente ainda ao "privá-la das atividades de pesquisas que devem caracterizar o ensino superior". Compreende-se nesse sentido que as diretrizes de formação docente são constantemente repensadas e redirecionadas a partir desses organismos multilaterais e seus respectivos interesses e pela reestruturação e ressignificação da educação básica atreladas às exigências de um novo perfil de trabalhador adequadas à sociedade contemporânea. Com esse tipo de formação perde-se a essência do conhecimento e a possibilidade da educação contribuir com a transformação da realidade.

Nesta ótica, apresentam-se ainda a formação continuada em serviço, amparada na LDB, lei ño 9.394/96, que trata dos profissionais da educação, no Título VI, Art. 61, Parágrafo único, ao afirmar que: "a formação de professores de modo a atender às especificidades do exercício de suas atividades, bem como aos objetivos das diferentes etapas e modalidades da educação básica, terá como fundamentos a presença de sólida formação básica, associação entre teorias e práticas, capacitação em serviço e aproveitamento de estudos anteriores, dentre outros".

Constitui-se, pois, a formação de professores pelas prerrogativas legais, expressas na LDB $n^{\circ}$. 9.394/96, regulamentada por meio do Decreto $n^{\circ}$. 6.755, de 29 de janeiro de 2009, que institui a Política Nacional de Formação de Profissionais do Magistério da Educação Básica, ao tratar sobre a formação inicial e continuada dos professores, revogado pelo Decreto $\mathrm{n}^{\mathrm{o}}$. 8.752, de 09 de maio de 2016. No que diz respeito à formação continuada, assegura no Inciso X: "o reconhecimento das instituições educativas e demais instituições de educação básica como espaços necessários à formação inicial e à formação continuada" (BRASIL, 2016).

O Plano Nacional de Educação 2014/2024 lança como uma das prioridades o objetivo de consolidar a política nacional de formação de professores e professoras da educação básica, definindo diretrizes nacionais, áreas prioritárias, instituições formadoras e processos de certificação das atividades formativas. Além disso, no que diz respeito à formação continuada de professores, destaca a necessidade de elaboração de planejamento estratégico, a melhoria contínua da qualidade educacional, a formação continuada dos(as) profissionais da educação e o aprimoramento da gestão democrática como uma das estratégias para melhorar o IDEB. Neste sentido, não se pode deixar de salientar que o IDEB apresenta-se como uma das ações da política nacional de avaliação que atende ao plano de metas para a política educacional brasileira, fundamentado no "Compromisso Todos pela Educação", cujo acordo orienta o processo de avaliação e cuja organização é composta por empresas, com atuação 
predominante no setor financeiro internacional e nacional. Dentre eles: O Grupo Gerdau, o Grupo Suzano, o Banco Bradesco, o Banco Itaú-Unibanco, as organizações Globo, constituindo-se como realidade a partir da aprovação do Decreto-Lei $n^{\circ}$. 6.094, de abril de 2007. Consolida-se nesta ótica um Estado Avaliador (AFONSO, 1999).

A partir das definiç̧ões expressas na legislação, resultantes dos acordos e orientações, instalam-se: um processo de profissionalização da carreira docente, que envolve a elaboração dos Planos de Carreira dos professores por parte dos entes federados, expresso nos planos de cargos, carreiras e salários e os processos de formação continuada. No estado do Ceará, e neste estudo, no município de Fortaleza, conforme dados obtidos pelo Grupo de Pesquisa GEPPE/UFC ${ }^{4}$, a formação também tem seguido a lógica, premissas e concepções estabelecidas a partir das prerrogativas legais e limites impostos pelas organizações internacionais, atende às determinações no que se refere à avaliação de seu desempenho, dos resultados escolares e fundamentalmente à premiação de alunos e professores (por bom desempenho), como se observa a seguir.

\section{A formação continuada de professores em Fortaleza}

O município de Fortaleza no Plano Municipal de Educação - PME - apresenta ações e diretrizes para a formação de professores em serviço. Fortaleza teve seu PME anterior (que durante o ano de 2015, período em que esta pesquisa foi realizada, ainda estava em vigor), promulgado em 30 de dezembro de 2008, resultando na Lei $n^{\circ}$. 9.441/2008, com duração de dez anos. Trata-se de um documento que aponta para a implementação de políticas públicas para formação inicial e continuada de professores como possibilidade para a mudança estrutural no ensino das escolas públicas.

O PME de Fortaleza (2008/2015), tendo como base o que está expresso no Plano Nacional de Educação - PNE - de $2001^{5}$, estabelece que se deva ter como pressupostos para a valorização dos profissionais da educação:

Uma formação profissional que assegure o desenvolvimento da pessoa do educador enquanto cidadão e profissional, o domínio dos conhecimentos objeto de trabalho com os alunos, e dos métodos pedagógicos que promovam a aprendizagem (FORTALEZA, 2008).

${ }^{4}$ GEPPE/UFC- Grupo de Estudos e Pesquisas em Política Educacional da Universidade Federal do Ceará Faculdade de Educação - Departamento de Fundamentos da Educação.

${ }^{5}$ Lei $\mathrm{n}^{\mathrm{o}}$. 10.172/2001. 
Pimenta (2005) argumenta em relação às propostas governamentais para a formação de professores que elas se fundamentam, muitas vezes, em conceitos que ficam apenas restritos à retórica e não promovem uma significativa alteração da realidade. Isso gera: “[...] políticas de formação contínua [...] fragmentadas [...] acompanhadas de explícitas e, às vezes sutis, desqualificações das universidades para realizar esta formação [...]" (PIMENTA, 2005, p. 40-41, grifo da autora).

No ano de 2015, o município de Fortaleza aprovou seu novo Plano Municipal de Educação, com duração de dez anos: 2015-2025, consolidado por meio da Lei $\mathrm{n}^{\circ}$. 10.371/2015, alinhado ao Plano Nacional de Educação, Lei n ${ }^{\circ}$. 13.005, de 25 de junho de 2014, e revoga a Lei $n^{\circ}$. 9.441, de 30 de dezembro de 2008 (do PME anterior), do Poder Executivo Municipal.

O referido plano apresenta como Meta 3: "Formar 50\% dos professores da educação básica em nível de pós-graduação lato e stricto sensu e garantir toda a formação continuada em sua área de atuação”. A Meta 3.10.4 do PME/2015, apresenta a seguinte estratégia para a formação de professores no âmbito municipal:

Garantir, em regime de colaboração com a União e o Estado, no prazo de um ano de vigência deste PME, política municipal de formação e valorização dos profissionais da educação, assegurando que todos os professores da educação básica possuam formação especifica de nível superior, obtida em curso de licenciatura na área de conhecimento em que atuam.

Nesta esteira, os dados levantados até o momento sobre a formação continuada de professores em serviço no município de Fortaleza evidenciam que: a) a formação acontece em espaços definidos pela SME, distante das escolas onde os professores trabalham; b) a formação acontece uma vez ao mês; c) nos encontros de formação reúnem-se os professores por disciplinas afins; d) os encontros reúnem professores de diferentes escolas; e) as formações são coordenadas pelos formadores da SME; f) os professores recebem formação para a organização e disciplinamento das salas de aula; g) nas formações são trabalhadas dinâmicas de sala de aula e jogos; h) os textos - em forma de artigos - trabalhados são de vários autores; i) não especifica a teoria pedagógica, nem o projeto de formação que a gestão pretende desenvolver com seus professores; $j$ ) as formações se voltam para os problemas individuais e muitas vezes subjetivos. Nesse caso, as atividades de formação corroboram com a firmação de Lukács de que:

Reflete-se, aqui no indivíduo, o fato de que, na sociedade capitalista, as atividades profissionais especializadas dos homens tornam-se aparentemente autônomas do processo global. Mas, enquanto o marxismo interpreta esta 
contradição, como um efeito da oposição entre produção social e apropriação privada o aparente contraste superficial é apresentado, pela ciência da decadência como "destino eterno dos homens" (LUKÁCS, 1978, p. 66).

Ainda, como assegura Lukács,

A decadência ideológica surge quando as tendências da dinâmica objetiva da vida cessam de ser reconhecidas, ou são mais ou menos ignoradas, ao passo que se introduzem em seu lugar desejos subjetivos, vistos como a força motriz da realidade (LUKÁCS, 1978, p. 93).

Severino (2004) chama a atenção para aspectos como a fragilidade epistêmica, a carência de postura investigativa na formação docente e a insuficiência da prática no processo formativo dos professores. Destaca ainda a formação disciplinar que conduz à visão de um mundo fragmentado, incapaz de dar conta da complexidade do trabalho docente. Nesta conjuntura, corre-se o risco de a formação apenas atender ao padrão pragmático-utilitário que altera a natureza do conhecimento.

Os professores entrevistados das onze escolas possuem curso superior, entretanto, não indicam tratar-se de curso de licenciaturas ou não (SME/2015). O percentual de funções docentes com curso superior por etapa/modalidade de ensino da rede municipal de ensino de Fortaleza, conforme INEP/SEDUC de 2014, indicam que: $92 \%$ dos professores que trabalham na educação infantil possuem curso superior; $98 \%$ dos que trabalham no ensino Fundamental e $98 \%$ dos que trabalham na Educação de Jovens e Adultos. No caso de estabelecer um comparativo com o índice brasileiro de 2013, conforme o Observatório do PNE, que é de $74,8 \%$ docentes com curso superior e $65,4 \%$ que possuem curso com licenciatura, em Fortaleza os dados são positivos.

Nem os documentos da SME, nem da Coordenadoria de Gestão de Pessoas, convém destacar, apresentam indicativos explícitos sobre a formação continuada e, neste enfoque, as considerações que são trazidas neste trabalho foram fornecidas pelos professores entrevistados e escolas pesquisadas.

No que diz respeito às avaliações às quais os estudantes, professores e escolas são submetidos, além de atenderem aos pressupostos previstos nas avaliações em larga escala, são consideradas pela gestão municipal, que utiliza o sistema de premiação aos "melhores" como um incentivo, ou, segundo o prefeito municipal: "empurrãozinho a mais para vocês darem o sangue, recuperarem o fôlego nessa reta final e apostarem em vocês. A gente acredita em vocês, de verdade" (FORTALEZA, 2015). Ainda, conforme salienta o prefeito: "o sucesso do projeto é resultado da crença e do esforço dos alunos, que assistem aulas com os melhores 
professores da cidade e recebem material de estudo competitivo". Neste aspecto, cabe aos professores da rede trabalhar para que seus alunos sejam os melhores, estabelecendo a competição e o ranqueamento entre as escolas.

Ao considerar a política de formação do município e as concepções de educação que a permeiam, constata-se, por meio das falas dos professores, que na formação continuada os resultados das avaliações são discutidos e os professores são instruídos para que seus alunos e suas escolas sejam premiados. Com isso se ratificam as hipóteses da pesquisa no que diz respeito ao tipo de formação e ideário que a permeia. Reafirmam-se concepções de mundo e de sociedade na lógica neoliberal, afinal, com os "melhores professores e esforço dos alunos" se estabelece a relação entre a igualdade meritocrática, igualdade de oportunidades, do princípio da justiça como equidade, ou seja, da justiça como igualdade de oportunidades. A propagação das concepções que consolidam o contexto destacado reforça as iniciativas de realização de programas "educativos e formativos" para a competitividade, uma vez que a educação contribui com os modelos de produção.

Estes princípios são naturalizados no modo de produção capitalista, sob a égide do neoliberalismo, e atendem ao conjunto de reformas que o Banco Mundial prescreve e que deverão ser seguidas, à medida que age como avaliador e fiscalizador das políticas implementadas (AFONSO, 1998), determinando a condução das ações.

\section{Considerações finais}

Os dados obtidos com esta pesquisa evidenciam, por um lado, o atendimento às prerrogativas legais e orientações dos organismos internacionais, com força nos espaços da macro e micropolíticas e, por outro lado, contradições na compreensão dos processos de formação continuada dos professores

Estas podem ser observadas pela maneira como têm sido conduzidas as formações dos professores, em uma lógica taylorista-fordista, vista pela fragmentação, isolamento, centralização, por vezes amparada na organização toyotista, por meio do qual se coloca para os indivíduos a responsabilidade pelos problemas, bem como a resolução. Uma destas situações se evidencia à medida que os gestores das escolas não têm autonomia para organizar as formações no espaço das escolas nem decidir com seus pares qual o tipo de formação. Ainda, por um lado, sob muitos aspectos, como salientaram os sujeitos da pesquisa, os gestores são considerados como cargos de confiança da administração e, por outro lado, os próprios colegas acabam controlando o trabalho e a formação dos demais. 
Os dados coletados indicam ainda que neste contexto o Estado em sua feição neoliberal e a ideologia da globalização pressionam a educação, imprimindo mudanças na formação de professores, sendo que esta passou a ser adquirida em novos lócus e as concepções presentes conduzem à subserviência às ordens do capital. Estas políticas revelam adesão ideológica dos governos à lógica neoliberal.

Outro aspecto interessante diz respeito ao fato de as formações dos professores não tratarem sobre a formação humana, mas insistirem no aspecto competitivo, pois dificilmente os professores formados na lógica da competição contribuem com a humanização dos indivíduos sob sua responsabilidade. A formação, nesse sentido, poderia se apresentar como um espaço fértil para discutir estas questões. Por ser um espaço constituído, entretanto, reafirma a concorrência entre os pares.

Nesta perspectiva, compreende-se a importância de intensificar pesquisas na rede municipal de ensino de Fortaleza, considerando a utilização efetiva dos espaços de formação dos professores em serviço, bem como a construção de uma identidade para as instituições educativas calcada em princípios que se identifiquem com a formação humana emancipatória.

\section{REFERÊNCIAS}

AFONSO, A. J. Estado, mercado, comunidade e avaliação. Esboço para uma rearticulação crítica. Educação \& Sociedade, Campinas: CEDES, v. 20, n. 69, p. 139-164, dez. 1999.

BRASIL. Constituição da República Federativa do Brasil. Brasília: Imprensa Oficial, 1988.

BRASIL. Ministério da Educação. Lei no 9.394/96, de 20 de dezembro de 1996. Lei de Diretrizes e Bases da Educação Nacional. Disponível em: www.planalto.gov.br/ccivil_03/leis/19394.htm. Acesso em: 30 mar. 2015.

BRASIL. Referenciais para formação de professores polivalentes: proposta para organização curricular e institucional. Secretaria do Ensino Fundamental: 1998. Disponível em: http://www.mec.gov.br. Acesso em: 13 jul. 2015.

BRASIL. Decreto $\mathbf{n}^{\mathbf{0}} 6755$ de 2009. Institui a Política Nacional de formação de profissionais da Educação Básica. Disponível em: http://www.planalto.gov.br/ccivil_03/_ato2007201h0/2009/decreto/d6755.htm.

BRASIL. Lei no 13005 de 25 junho de 2014. Aprova o Plano Nacional de Educação- PNE e dá outras providências. Disponível em: https://www.planalto.gov.br/ccivil_03/_ato20112014/2014/lei/l13005.htm. Acesso em: 13 jul. 2015.

BRASIL. Observatório do PNE - Formação de professores. Disponível em: http://www.observatoriodopne.org.br/metas-pne/15-formacao-professores/indicadores. 
BUENO, M. S. S. O Banco Mundial e modelos de gestão educativa para a América Latina. Cadernos de Pesquisa. v. 34, n. 122 São Paulo maio/ago., 2004.

CASASSUS, J. Tarefas da educação. Tradução: Oscar Calavia Sáez. Campinas: Autores Associados, 1995.

FORTALEZA, CE. Plano de Cargos, Carreiras e Salários, lei nº 9249, de 10 de julho de 2007. Disponível em:

http://www.sme.fortaleza.ce.gov.br/educacao/index.php/conteudos/category/81-legislacaoeducacional. Acesso em: 30 mar. 2015.

FORTALEZA, CE. Sistema Municipal de Educação, lei n 9317, de 14 de dezembro de 2007. Disponível em:

http://www.sme.fortaleza.ce.gov.br/educacao/index.php/conteudos/category/81-legislacaoeducacional. Acesso em: 30 mar. 2015.

FORTALEZA, CE. Plano Municipal de Educação, lei no 9441, de 30 de dezembro de 2008. Disponível em:

http://www.sme.fortaleza.ce.gov.br/educacao/index.php/conteudos/category/81-legislacaoeducacional. Acesso em: 30 mar. 2015.

FORTALEZA, CE. Lei Complementar n⿳0 0190, de 22 de dezembro de 2014. Disponível em: http://www.fortaleza.ce.gov.br/sites/default/files/arquivos/diariosoficiais/14/12/22122014__15430_0.pdf. Acesso em: 30 mar. 2015.

FORTALEZA, CE. Formação Docente. Disponível em:

http://www.sme.fortaleza.ce.gov.br/educacao/index.php/conteudos/category/602-funcaodocente.

KOZIK, K. Dialética do Concreto. Rio de Janeiro: Paz e Terra, 3. ed., 1985.

KUENZER, A. Z. As políticas de formação: A constituição da identidade do professor sobrante. Educação \& Sociedade, ano XX, n. 68, dez. 1999.

LEHER, R. Um Novo Senhor da educação? A política educacional do Banco Mundial para a periferia do capitalismo. Revista Outubro, 2014. Disponivel em:

http://www.revistaoutubro.com.br/edicoes/03/out3_03.pdf. Acesso em: out. 2014.

LUKÁCS, G. As bases ontológicas do pensamento e da atividade do homem. Temas de Ciências Humanas. São Paulo, Livraria Editora das Ciências Humanas Ltda, 1978.

MOREIRA, S. V. Análise documental como método e como técnica. In: DUARTE, Jorge; BARROS, Antonio (org.). Métodos e técnicas de pesquisa em Comunicação. São Paulo: Atlas, 2005.

PIMENTA, S. G. Professor reflexivo: construindo uma crítica. In: GHEDIN, E. (orgs.) Professor reflexivo no Brasil: gênese e crítica de um conceito. São Paulo: Cortez, 2005. 
ROMANELI, O. O. História da Educação no Brasil (1930/1973). Petrópolis: Editora Vozes, 1978.

SAVIANI, D. Pedagogia Histórico-Crítica: primeiras aproximações. 11. ed. Campinas, SP: Autores Associados, 2000.

SEVERINO, A. J. A formação e a prática do professor em face da crise atual dos paradigmas educacionais. Ciência \& Opinião, v. 1, n. 2/4, p. 15-31, 2004.

SHIROMA. Eneida. Política de Profissionalização: Aprimoramento ou desintelectualização do Professor. Intermeio: revista do Mestrado em Educação, Campo Grande, MS, v. 9, n. 17, p. 64-83, 2003.

UNESCO, 2008. Disponível em: http://www.UNESCO.org/new/pt/brasilia/about-thisoffice/networks/un-system-and-international-organisms/. Acesso em: 19 jan. 2015.

\section{Como citar este artigo:}

ZIENTARSKI, Clarice; FREIRE, Perla de Almeida; LIMA, Maria Aires. A formação de professores em serviço: políticas de alinhamento aos organismos internacionais e à lógica liberal. Revista Ibero-Americana de Estudos em Educação, Araraquara, v. 14, n. 4, p. 2160-2174, $\quad$ out./dez., $2019 . \quad$ e-ISSN: $1982-5587 . \quad$ DOI: https://doi.org/10.21723/riaee.v14i4.8545

Data de Submissão: 03/05/2016

Revisões requeridas: 11/05/2017

Aceite em: 19/02/2018

Publicado em: 02/09/2019 